\title{
Increased goiter prevalence in schoolchildren of Isfahan despite long-term iodine sufficiency
}

\author{
Mansour Siavash ${ }^{1}$, Ammar Hassanzadeh Keshteli ${ }^{1,2}$, Mahin Hashemipour ${ }^{1}$, \\ Masoud Amini ${ }^{1}$ \\ ${ }^{1}$ Isfahan Endocrine and Metabolism Research Center, Isfahan University of Medical Sciences, ${ }^{2}$ Medical Students \\ Research Center, School of Medicine, Isfahan University of Medical Sciences, Isfahan, Iran
}

\begin{abstract}
OBJECTIVE: Iodine Deficiency (ID) was for years considered a contributing factor for endemic goiter in Iran. The present study was conducted to assess the goiter prevalence and iodine status in schoolchildren of Isfahan 16 years after the initiation of salt iodization in Iran. DESIGN: 2331 schoolchildren, aged 6-13 years were selected by multistage random sampling. Thyroid size was estimated in each child by inspection and palpation and was graded according to the criteria recommended by WHO. Urinary Iodine Concentration (UIC) was also measured. RESULTS: Overall, $32.9 \%$ of the 2331 students had goiter. $4.6 \%$ of them were classified as goitrous grade 2. The median UIC was $195.5 \mu \mathrm{g} / \mathrm{l}$ (Range: $10-580 \mu \mathrm{g} / \mathrm{l}) .15 .8 \%$ of total samples had iodine excretion level below $100 \mu \mathrm{g} / \mathrm{l}$ and $3.7 \%$ had iodine level below $50 \mu \mathrm{g} / \mathrm{l}$. UIC in nongoitrous and goitrous children was $($ mean \pm SD) $220.91 \pm 119.44 \mu \mathrm{g} / \mathrm{l}$ and $220.16 \pm 114.64 \mu \mathrm{g} / \mathrm{l}$, respectively $(p=0.949)$. CONCLUSION: According to the present study there is no biochemical ID and the iodine intake of the total population is adequate. Goiter prevalence has decreased significantly after the new legislation, nevertheless it is still a public health problem in this region. The data suggest that other goitrogens, micronutrient deficiencies and thyroid autoimmunity may be operative and must be investigated in Isfahan schoolchildren.
\end{abstract}

Key words: Goiter, Iodine, Iran, Schoolchildren

\section{INTRODUCTION}

Iodine Deficiency (ID) is recognized as a major preventable public health problem worldwide. It is

\section{Address for correspondence:}

Ammar Hassanzadeh Keshteli, Medical Students Research Center and Isfahan Endocrine and Metabolism Research Center, Isfahan University of Medical Sciences, Hezarjarib Street, Isfahan, Iran, Tel: +98 9357281070 ,

Fax: +98 311337 3733, e-mail: hasanzadeh@med.mui.ac.ir

Received 23-07-08, Revised 10-10-08, Accepted 30-10-08 estimated that 750 million people worldwide are at risk of Iodine Deficiency Disorders (IDD). ${ }^{1}$ IDD can be presented with a wide variety of clinical manifestations, which induce congenital anomalies, cretinism, deaf mutism, psychomotor defects and severe goiter. ${ }^{2}$

Endemic goiter had been present in most parts of $\operatorname{Iran}^{3}$ and for several years ID was considered a contributing factor for endemic goiter in this country. ${ }^{4}$ Iran's National Committee for Control of IDD was initiated in 1989 by the Ministry of Health and 
Medical Education. The production and distribution of iodized salt, with $40 \mathrm{mg}$ of potassium iodide per $\mathrm{kg}$ of sodium chloride, was then started and the education of policymakers, health personnel and the public was initiated in 1990. However, a rapid survey in 1993 of iodized salt consumption showed that less than $50 \%$ of the population consumed iodized salt with mean urinary iodine ranging from 5.0 to $8.2 \mu \mathrm{g} / \mathrm{dl}$. As a result, the first law requiring the mandatory iodization of all salts for household use was proclaimed in $1994 .^{5}$

Isfahan is a city in the central part of Iran with an approximate population of 2,000,000. The prevalence of goiter in Isfahan had been estimated in 1989 to be 92\% in girls and $85 \%$ in boys. ${ }^{6}$ According to another study conducted in 1997 the prevalence of goiter among Isfahan 6-18-year-old children was estimated to be $62 \%{ }^{7}$

The present study was conducted to estimate goiter prevalence and urinary iodine concentration in Isfahan schoolchildren 16 years after the initiation of salt iodization in this city.

\section{METHODOLOGY}

This was a cross-sectional study performed on schoolchildren of Isfahan in 2005. Subjects were enrolled with a multistage cluster random sampling. We excluded subjects with a history of exposure to radioactive iodine, thyroid surgery or significant underlying disease such as cardiopulmonary, liver or renal problems based on available medical records and interviews with parents and teachers.

Goiter grading was performed by two endocrinologists according to $\mathrm{WHO} / \mathrm{UNICEF} / \mathrm{ICCIDD}$ classification: ${ }^{1}$

Grade 0: No palpable or visible goiter;

Grade 1: A goiter that is palpable but not visible when the neck is in the normal position (i.e. the thyroid is not visibly enlarged);

Grade 2: A swelling in the neck that is clearly visible when the neck is in a normal position and is consistent with an enlarged thyroid when the neck is palpated.

Weight and standing height were measured. Height was recorded to the nearest $0.1 \mathrm{~cm}$ and weight was recorded to the nearest $100 \mathrm{~g}$. Body Mass Index (BMI) was calculated using the following formula: BMI=weight $(\mathrm{Kg}) /$ height $(\mathrm{m})^{2}$. Body surface area (BSA) was calculated by the formula: weight $(\mathrm{Kg})$ ${ }^{0.425} \times$ height $(\mathrm{cm})^{0.725} \times 71.84 \times 10^{-4}$.

The blood samples were transferred on dry ice to the reference laboratory of the "Isfahan Endocrine and Metabolic Research Center". The samples were stored at $-70^{\circ} \mathrm{C}$ until analysis. All urine and blood assays were performed within a median of $26 \mathrm{~h}$ of sampling. The same person performed each assay using the same method.

Urine Iodine Concentration (UIC) was determined by the digestion method based on a modification of Sandell-Kolthoff reaction ${ }^{1,8}$ (intra-assay CV $1.2 \%$ and inter-assay CV 2.2\%).

Serum T4 concentration was measured by radioimmunoassay (Iran Kavoshyar Co., Tehran, Iran) (Intra-assay CV $4.7 \%$ and inter-assay CV 4.9\%). Normal range for T4 level was 4.5-12 $\mu \mathrm{g} / \mathrm{dl}$. Serum TSH concentration was determined with immunoradiometric assay (Iran Kavoshyar Co., T ehran, Iran) (Intra-assay CV $1.5 \%$ and inter-assay CV 1.9\%). Normal range for TSH level was 0.3-3.9 mIU/l. Overt hypothyroidism was defined as elevated TSH and low $\mathrm{T} 4$, subclinical hypothyroidism as elevated TSH and normal T4 and subclinical hyperthyroidism as low $\mathrm{TSH}$ and normal T4.

Quantitative variables are presented as mean \pm SD. Normality of data distribution was assessed with the Kolmogorov-Smirnov test. Independent sample t-test and one-way ANOVA were used to compare normally distributed measurements in different groups. Parameters not normally distributed were compared by the Mann-Whitney U or KruskalWallis $\mathrm{H}$ tests. Prevalence of goiter in boys and girls was compared by the chi-square test. Correlation between quantitative variables was calculated by Pearson correlation coefficient. $P$ value less than 0.05 was considered statistically significant. All analysis was performed using SPSS version 15 (SPPS Corp, Chicago, IL, USA).

Written consent was obtained from all children's parents who were informed about the study. The study was approved by the Ethics Committee of the 
Isfahan Endocrine and Metabolism Research Center of Isfahan University of Medical Sciences.

\section{RESULTS}

Two thousand three hundred and thirty-one schoolchildren were enrolled in this study with female to male ratio of 1.60. Their age ranged from 6 to13 years. The mean age \pm SD was $9.39 \pm 1.18$ years for girls and $9.47 \pm 1.12$ years for boys. Overall, $32.9 \%$ of subjects were classified as goitrous (Table 1). Goiter prevalence among girls was $32.4 \%$ while $33.7 \%$ of boys were goitrous $(\mathrm{P}=0.518)$.

UIC was measured in 454 schoolchildren. The mean \pm SD and median UIC was $220.66 \pm 17.33$ and $195.50 \mu \mathrm{g} / \mathrm{l}$, respectively. Table 2 shows the mean, values, the range, as well as the 10th, 25th, 50th, 75th and 90th percentiles of UIC by goiter status. $15.8 \%$ of total samples had iodine excretion level below $100 \mu \mathrm{g} / \mathrm{l}$ and $3.7 \%$ had iodine level below $50 \mu \mathrm{g} / \mathrm{l} .25 .6 \%$ of subjects had UIC between 200 and $300 \mu \mathrm{g} / \mathrm{l}$ and $23.8 \%$ had UIC more than $300 \mu \mathrm{g} / \mathrm{l}$. UIC in nongoitrous and goitrous children was $220.91 \pm 119.44$ and $220.16 \pm 114.64 \mu \mathrm{g} / \mathrm{l}$, respectively $(\mathrm{P}=0.949)$. There

Table 1. Thyroid size determined by inspection and palpation in schoolchildren of Isfahan, Iran

\begin{tabular}{llccc}
\hline & & \multicolumn{3}{c}{ Thyroid size } \\
\cline { 3 - 5 } & Number & Nongoitrous & Grade 1 goiter & Grade 2 goiter \\
\hline Boys & 898 & $66.3 \%$ & $27.3 \%$ & $6.4 \%$ \\
Girls & 1433 & $67.6 \%$ & $29 \%$ & $3.4 \%$ \\
All & 2331 & $67.1 \%$ & $28.3 \%$ & $4.6 \%$ \\
\hline
\end{tabular}

was also no significant difference in UIC levels between nongoitrous subjects and children with grade 1 or grade 2 goiter. UIC did not differ significantly in boys and girls $(221.25 \pm 123.99$ vs. $220.16 \pm 112.53$ $\mu \mathrm{g} / \mathrm{dl}, \mathrm{P}=0.922)$. The mean $\pm \mathrm{SD}$ of UIC in goitrous and nongoitrous boys was $215.70 \pm 118.02 \mu \mathrm{g} / \mathrm{l}$ and $223.93 \pm 127.09 \mu \mathrm{g} / \mathrm{l}$, respectively $(\mathrm{P}=0.657)$. UIC in goitrous and nongoitrous girls was $223.68 \pm 112.49$ and $218.33 \pm 112.85 \mu \mathrm{g} / \mathrm{l}$, respectively $(\mathrm{P}=0.723)$. No significant relationship was found between UIC and different goiter grades.

Serum T4 and TSH were measured in 485 children. All children had T4 levels within normal range. There were $6(1.2 \%)$ children with subclinical hyperthyroidism and $82(16.9 \%)$ children with subclinical hypothyroidism. Goitrous children had significantly lower T4 levels than nongoitrous ones $(8.46 \pm 1.47 \mathrm{vs}$. $8.84 \pm 1.48 \mu \mathrm{g} / \mathrm{dl}, \mathrm{P}=0.008$ ) (Table 3 ). There was no significant difference between TSH levels in goitrous and nongoitrous children ( $3.18 \pm 3.96$ vs. $2.65 \pm 1.36$ $\mathrm{mIU} / \mathrm{l}, \mathrm{P}=0.098$ ). However, comparing TSH levels

Table 3. TSH and T4 levels in schoolchildren of Isfahan according to goiter status

\begin{tabular}{lcccc}
\hline & & Number & TSH $(\mathbf{m I U} / \mathbf{l})$ & $\mathbf{T 4}(\boldsymbol{\mu g} / \mathbf{d l})^{\mathrm{a}}$ \\
\hline Nongoitrous & & 323 & $2.65 \pm 1.36^{\mathrm{a}}$ & $8.84 \pm 1.48^{\mathrm{b}}$ \\
Goiter & Total & 162 & $3.18 \pm 3.96$ & $8.46 \pm 1.47^{\mathrm{c}}$ \\
& Grade 1 & 68 & $2.66 \pm 1.10$ & $8.81 \pm 1.10$ \\
& Grade 2 & 94 & $3.56 \pm 5.09$ & $8.20 \pm 1.65$ \\
\hline
\end{tabular}

${ }^{a}$ To converts to SI units multiply by 12.87

${ }^{\mathrm{b}}$ Significant difference vs. goiter grade 2

${ }^{\mathrm{c}}$ Significant difference vs. nongoitrous

Table 2. The mean \pm SD, range and the 10th, 25th, 50th, 75th and 90th percentiles of values of Urinary Iodine Concentration (UIC) in $\mu \mathrm{g} / \mathrm{L}$ in Isfahan schoolchildren by goiter status

\begin{tabular}{lccccccccc}
\hline & & \multicolumn{9}{c}{ UIC $(\boldsymbol{\mu g} / \mathbf{l})$} \\
\cline { 3 - 10 } & & & & & $\mathbf{1 0}^{\text {th }}$ & $\mathbf{2 5}^{\text {th }}$ & $\mathbf{5 0}^{\text {th }}$ & $\begin{array}{c}\mathbf{7 5}^{\text {th }} \\
\text { Percentile }^{\text {Percentile }}\end{array}$ & $\begin{array}{c}\mathbf{9 0}^{\text {th }} \\
\text { Percentile }\end{array}$ \\
\hline Nongoitrous & & 302 & $220.91 \pm 119.44$ & $10-530$ & 85.60 & 126.75 & 198.50 & 300.00 & 420.00 \\
Goiter & Total & 152 & $220.16 \pm 114.64$ & $30-580$ & 89.00 & 134.00 & 192.00 & 286.00 & 410.00 \\
& Grade 1 & 62 & $240.45 \pm 121.66$ & $57-490$ & 97.90 & 136.00 & 209.50 & 352.50 & 420.00 \\
& Grade 2 & 90 & $206.19 \pm 108.03$ & $30-580$ & 83.10 & 130.00 & 188.50 & 264.25 & 355.70 \\
Overall & & 454 & $220.66 \pm 17.33$ & $10-580$ & 87.50 & 130.00 & 195.50 & 296.25 & 410.00 \\
\hline
\end{tabular}


in children according to the grades of goiter showed that children with grade 2 of goiter had significantly higher TSH levels than nongoitrous ones (Table 3).

UIC was not correlated with BMI, BSA, serum T4 and TSH levels.

\section{DISCUSSION}

Approximately $33 \%$ of schoolchildren in the present study were classified as goitrous, this implying that goiter is still endemic in this iodine replenished area and a severe public health problem according to WHO/UNICEF/ICCIDD recommended criteria. ${ }^{1}$

Iran has been known as a country in which goiter has frequently been seen in the population. The first goiter survey carried out in 1968 showed that goiter was prevalent in many provinces. ${ }^{3}$ In 1983, 15 years after the original study, with no program for the control of IDD, a series of investigations in Shahriar, Tehran, Kohkiloyeh and Boyerahmad were conducted, the findings of which showed high incidence of goiter in many regions. ${ }^{5}$ In schoolchildren of villages north and north-west of Tehran, manifestations of severe IDD such as defective physical, mental and psychomotor development, neurologic and auditory abnormalities along with frequent occurrence of hypothyroidism was found. ${ }^{9,10}$ The results of these studies prompted the formation of the National Committee for Control of IDD in 1989 and the national survey of goiter. ${ }^{6}$ The results of the survey showed that 20 provinces had a goiter rate of over $40 \%$. Urinary iodine excretion in many regions of the country was below $100 \mu \mathrm{g} / \mathrm{l}$ and in some less than $20 \mu \mathrm{g} / \mathrm{l}^{4,5}$ The salt iodization program began in 1989 and the production, distribution and consumption of iodized salt gradually increased. Qualitative and quantitative monitoring of iodized salt was applied on a regular basis in salt factories, retailers, shoppers and consumers in all provinces. Despite widespread education programs of health personnel and public between 1989 and 1994, the rapid survey of iodized salt consumption in 1994 showed that less than $50 \%$ of households consumed iodized salt. Therefore, a law was passed and the production of salt for household use was limited to $1 \mathrm{~kg}$ yellow bags containing iodized salt. Rapid surveys since 1996 have shown that more than $90 \%$ of households consume iodized salt. ${ }^{5}$
The present survey was conducted 16 years after the initiation of iodized salt production and 11 years after the implementation of the new law for mandatory consumption of iodized salt by households.

According to the present study, goiter prevalence in Isfahan decreased from about $89 \%$ in $1989^{6}$ and $62 \%$ in $1997^{7}$ to $32.9 \%$ in 2005 . This implies that ID has been the most important cause of endemic goiter and also shows the effective role of legislation and salt iodization in treating goiter. Goiter prevalence in the present study was higher than its prevalence in Gorgan (north of Iran) ${ }^{11}$ and comparable to Semirom (a mountainous city near Isfahan). ${ }^{12}$

The most sensitive method for the monitoring and evaluation of an IDD control program is the determination of urinary iodine excretion..$^{13}$ According to WHO/UNICEF/ICCIDD recommended criteria, the indicator of ID elimination is a median value for UIC of $100 \mu \mathrm{g} / \mathrm{l}$ and UIC should not be below $50 \mu \mathrm{g} / \mathrm{l}$ in more than $20 \%$ of samples. ${ }^{1}$ In the studied population, the median UIC was $195.50 \mu \mathrm{g} / \mathrm{l}$ and $3.7 \%$ of the population had UIC below $50 \mu \mathrm{g} / \mathrm{l}$. This means that there is no biochemical ID or no inadequacy in iodine intake of the overall population. According to $\mathrm{WHO} / \mathrm{UNICEF} / \mathrm{ICCIDD}$ criteria, $25.6 \%$ of subjects in our study had more than adequate iodine intake and $23.8 \%$ had excessive iodine intake. This indicates a risk of iodine-induced hyperthyroidism within 5 to 10 years after the introduction of iodized salt in susceptible groups. ${ }^{1}$ It has been reported that, after prophylaxis with iodized salt in Zaire, $14 \%$ of patients had undetectable serum TSH values. ${ }^{29} \mathrm{In}$ the present study, $1.2 \%$ of subjects had subclinical hyperthyroidism but there was no case of clinical hyperthyroidism. Although manual goiter palpation technique yields sufficiently precise quantitative results for clinical purposes, ${ }^{14}$ it also has some limitations. While goiter rate remains high after iodine supplementation, sonography may reveal significant changes in thyroid volume. ${ }^{15}$ Previous studies indicated that measurement of goiters by palpation may not be appropriate in short-term evaluation of iodization programs, though for long-term follow-up it can be reliable. ${ }^{16}$ However, even if our assessment of response to iodine replenishment is not adequately sensitive, the high prevalence of goiter in the area studied is undeniable. 
There are several studies showing serum TSH in the upper normal range in areas with endemic goiter. ${ }^{17-19}$ In the present study we found higher TSH levels in goitrous subjects than in nongoitrous ones.

In conclusion, goiter is still prevalent in Isfahan schoolchildren. ID alone cannot explain the endemic goiter in this region. The role of other possible contributors such as unknown goitrogens, ${ }^{20}$ autoimmunity ${ }^{12}$ or other micronutrient deficiencies such as vitamin $\mathrm{A},{ }^{21}$ iron, ${ }^{22}$ selenium ${ }^{23}$ and zinc deficiencies ${ }^{24}$ must be considered and should be investigated in Isfahan schoolchildren.

\section{ACKNOWLEDGMENTS}

This study was funded by the Bureau for Research, Isfahan University of Medical Sciences. We are grateful to the authorities of the provincial and local Education offices, and all the staff working with the project, students and their parents.

\section{REFERENCES}

1. WHO, UNICEF and ICCIDD, 2001 Assessment of iodine deficiency disorders and monitoring their elimination. A guide for programme managers. WHO/NHD/01.1. 2nd ed. Geneva: WHO.

2. Saggiorato E, Mussa A, Sacerdote C, et al, 2004 Thyroid volume and urinary iodine excretion in the schoolchild population of a Northwestern Italian sub-Alp metropolitan area. J Endocrinol Invest 27: 516-522.

3. Emami A, Shahbazi H, Sabzevari M, et al, 1969 Goiter in Iran. Am J Clin Nutr 22: 1584-1588.

4. Kimiagar M, Azizi F, Navai L, Yassai M, Nafarabadi $\mathrm{T}, 1990$ Survey of iodine deficiency in a rural area near Tehran: association of food intake and endemic goitre. Eur J Clin Nutr 44: 17-22.

5. Azizi F, Sheikholeslam R, Hedayati M, et al, 2002 Sustainable control of iodine deficiency in Iran: beneficial results of the implementation of the mandatory law on salt iodization. J Endocrinol Invest 25: 409-413.

6. Azizi F, Kimiagar M, Nafarabadi T, Yassai M, 1990 Current status of iodine deficiency disorders in the Islamic Republic of Iran. EMR Health Surv J 8:23-27.

7. Aminorroaya A, Amini M, Rezvanian H, et al, 2001 Effects of iodized salt consumption on goiter prevalence in Isfahan: the possible role of goitrogens. Endocr Pract 7: 95-98.

8. Pino S, Fang SL, Braverman LE, 1996 Ammonium persulfate: a safe alternative oxidizing reagent for measuring urinary iodine. Clin Chem 42: 239-243.

9. Azizi F, Sarshar A, Nafarabadi M, et al, 1993 Impairment of neuromotor and cognitive development in iodine deficient schoolchildren with normal physical growth. Acta Endocrinol 129: 501-504.

10. Azizi F, Kalani H, Kimiagar M, et al, 1995 Physical, neuromotor and intellectual impairment in non-cretinous schoolchildren with iodine deficiency. Int J Vitam Nutr Res 65: 199-205.

11. Bazrafshan HR, Mohammadian S, Ordookhani A, et al, 2005 Prevalence of goiter among schoolchildren from Gorgan, Iran, a decade after national iodine supplementation: association with age, gender, and thyroperoxidase antibodies. J Endocrinol Invest 28: 727-733.

12. Hashemipour M, Amini M, Aminorroaya A, et al, 2007 High prevalence of goiter in an iodine replete area: do thyroid auto-antibodies play a role? Asia Pac J Clin Nutr 16: 403-410.

13. Dunn JT, Van der Har F, 1990 A practical guide to the correction of iodine deficiency. The Netherlands: International Council for Control of Iodine Deficiency Disorders.

14. Nordmeyer JP, Simons M, Wenzel C, Scholten T, 1997 How accurate is the assessment of thyroid volume by palpation? A prospective study of 316 patients. Exp Clin Endocrinol Diabetes 105: 366-371.

15. Todd CH, Dunn JT, 1998 Intermittent oral administration of potassium iodide solution for the correction of iodine deficiency. Am J Clin Nutr 67: 1279-1283.

16. Jooste PL, Weight MJ, Lombard CJ, 2000 Short-term effectiveness of mandatory iodization of table salt, at an elevated iodine concentration, on the iodine and goiter status of schoolchildren with endemic goiter. Am J Clin Nutr 71: 75-80.

17. Bachtarzi H, Benmiloud M, 1983 TSH- regulation and goitrogenesis in severe iodine deficiency. Acta Endocrinol 103: 21-27.

18. Chopra IJ, Hershman JM, Hornabrook RW, 1975 Serum thyroid hormone and thyrothropin levels in subjects from endemic goiter regions of New Guinea. J Clin Endocrinol Metab 40: 326-333.

19. Thakur C, Saikia TC, Yadav RN, 1997 Total serum levels of triiodothyronine (T3), thyroxine (T4) and thyrotropine (TSH) in school going children of Dibrugarh district: and endemic goiter region of Assam. Indian J Physiol Pharmacol 41: 167-170.

20. Muros P, Ruiz-Lopez MD, Olea MF, 1992 Intake of iodine and major nutrients in an area of endemic goitre. J Nutr Sci Vitaminol (Tokyo) 38: 603-607.

21. Zimmermann MB, Wegmuller R, Zeder C, Chaouki N, Torresani T, 2004 The effects of vitamin A deficiency and vitamin A supplementation on thyroid function in goitrous children. J Clin Endocrinol Metab 89: 41-47. 
22. Zimmermann M, Adou P, Torresani T, Zeder C, Hurrell R, 2000 Persistence of goiter despite oral iodine supplementation in goitrous children with iron deficiency anemia in Ctte d'Ivoire. Am J Clin Nutr 71: 88-93.

23. Dabbaghmanesh MH, Sadegholvaad A, Ejtehadi F, Omrani G, 2007 Low serum selenium concentration as a possible factor for persistent goiter in Iranian school children. Biofactors 29: 77-82.

24. Zhang F, Liu N, Wang X, Zhu L, Chai Z, 2004 Study of trace elements in blood of thyroid disorder subjects before and after 131I therapy. Biol Trace Elem Res 97: $125-134$. 